\title{
VOLTAGE STABILITY IN POWER SYSTEM USING TEACHING LEARNING-BASED OPTIMIZATION TECHNIQUE
}

\author{
Shubham Patwari, V.K. Jain, Uttam Kumar Gupta \\ E-Mail Id: 2016pes5461@mnit.ac.in \\ Department of Electrical Engineering, Malaviya National Institute of Engineering, Jaipur, Rajasthan, \\ India
}

\begin{abstract}
The research represents the soft computing technique namely teaching learning-based optimization technique with the various flexible AC transmission system devices for interconnected power system for economic operation. In this paper the soft computing technique is used also for different reacting loadings. In these, two FACTS devices like SVC (Static Var compensator) and TCSC (Thyristor-controlled series capacitor) are utilized. The reactive loadings of the system have been gradually increased from $100 \%$ of base reactive loading. At last, the technique has been compared in respect to improvement of voltage.

Keywords: Var compensator (SVC), Flexible AC transmission system (FACTS), Thyristor controlled series capacitor (TCSC), reactive loading, TLBO, Reactive power flow.
\end{abstract}

\section{INTRODUCTION}

The electric power system is not always in balance condition. The prime object of the power system is to meet the demand with supply, deliver transmission loss compensation, regulation of voltage and frequency, reliability presentation etc. Various traditional optimization techniques have been utilized for this objective. Methods such as nonlinear programming technique, genetic algorithm are used to resolve such tasks. But it has many disadvantages such as lengthy numerical iteration, deficient convergence properties; which leads to long computation and maximum time for execution. These algorithms are higher utilized for power grid optimization, which are Hybrid Evolutionary Programming (HEP), Tabu Search (TS), Teaching learning based optimization (TLBO),Genetic Algorithm (GA), Evolutionary Programming (EP), Simulated Annealing (SA), Particle Swarm Optimization (PSO), Bacterial Foraging Optimization (BFO), Gravitational Search Algorithm (GSA), and many more are developed these provides quick and excellent solution. With the help of such techniques we can improve voltage of the system. The control of reactive power is a big issue for different aspects. One, due to fuel cost the operation of power system must be economical, is the prime requirement.

\section{FACTS DEVICES}

FACTS are the devices which may be installed into power systems nonparallel, in parallel, and in various cases they are connected in series and shunt. For power transmission and distribution in special cases fastened Series Capacitors (SC), SVC (Static Var Compensators), moreover as STATCOM and Thyristor-Controlled Series Capacitors (TCSC). SC and SVC are utilized for a particular period. The primary installation of Shunt Capacitors came in picture within the early Nineteen Fifties.

\subsection{Static Var Compensator (SVC)}

The Static Var Compensator (SVC) is a primary age FACTS device is obsessed for research. It's a changeable impedance instrument. Wherever the current along a reactor is managed mistreatment cascade connected thyristor valves. the applying of thyristor valve mechanism to SVC is an overshoot of the advancement in HVDC. The foremost distinction is that for low rating of voltages thyristor valves are utilized in SVC because in an extra high voltage line we connect the SVC through a step down transformer or through the tertiary winding of power transformer. The SVC (static Var compensator) is a device which can be connected in shunt of the line as a reactive power source or sink as requirement. Its output can also be controlled or managed by the controlling of the inductive or capacitive current to control the specific parameters of the system or the bus voltage.

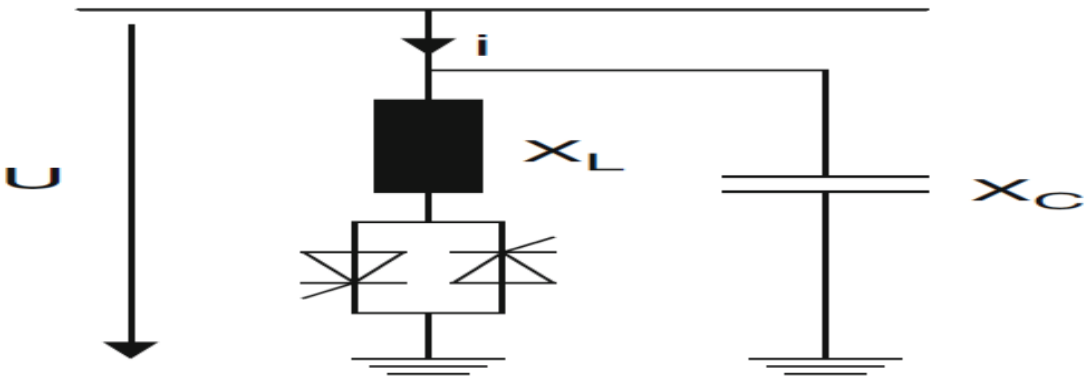

Fig. 2.1 Single Phase Equivalent Circuit of SVC 
ICRDET-2019, September 14-15, 2019, AICE, Jaipur, India

International Journal of Technical Research \& Science (Special Issue) ISSN No.:2454-2024 (online)

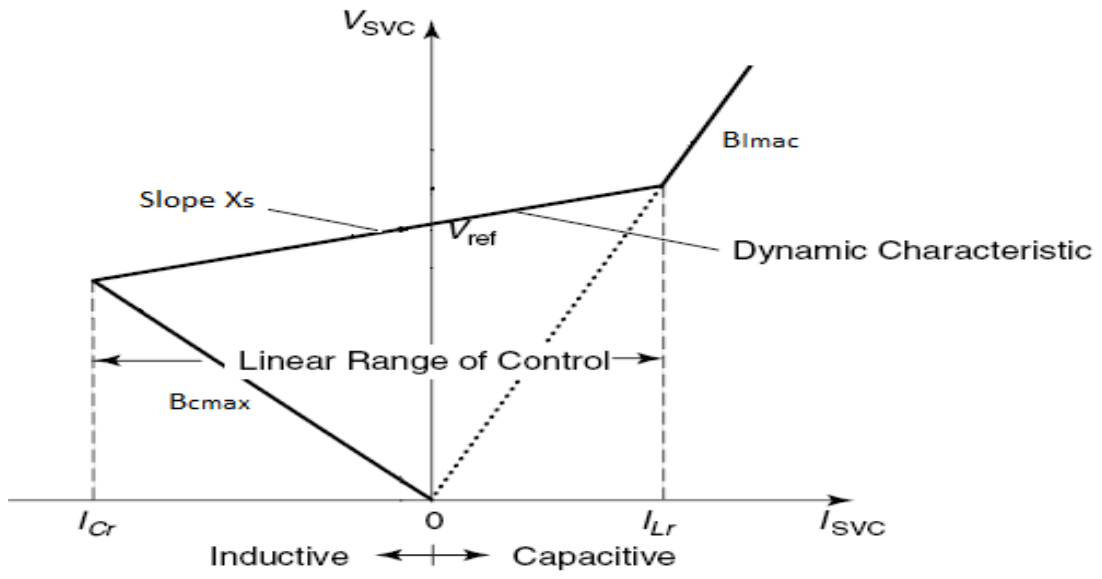

Fig. 2.2 SVC VI Characteristics

\subsection{Thyristor controlled series capacitor (TCSC)}

Thyristor Controlled Series capacitor (TCSC) provides powerful suggests that of controlling and increasing power transfer level of a system by variable the apparent impedance of a particular line. A TCSC will be used in a much planned approach for contingencies to reinforce power grid stability. Using TCSC, it's potential to work stably at seventy five power levels well on the far side those that the system was originally supposed while not endangering system stability. With the exception of this, TCSC is additionally being employed to mitigate SSR (sub synchronous resonance).

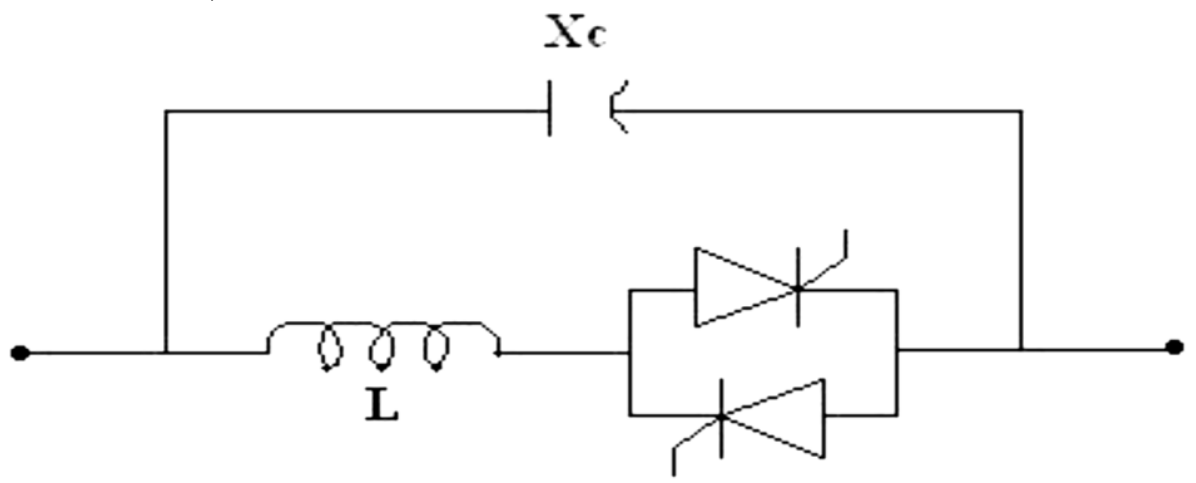

Fig. 2.3 Basic Scheme of TCSC

TCSC may be a series compensating FACTS device mistreatment to regulate power flow in transmission lines and improves transient stability in power grid. TCSC controls the power flow in transmission lines by varied the ohmic resistance of TCSC by dominant the delay angle of thyristor valves.

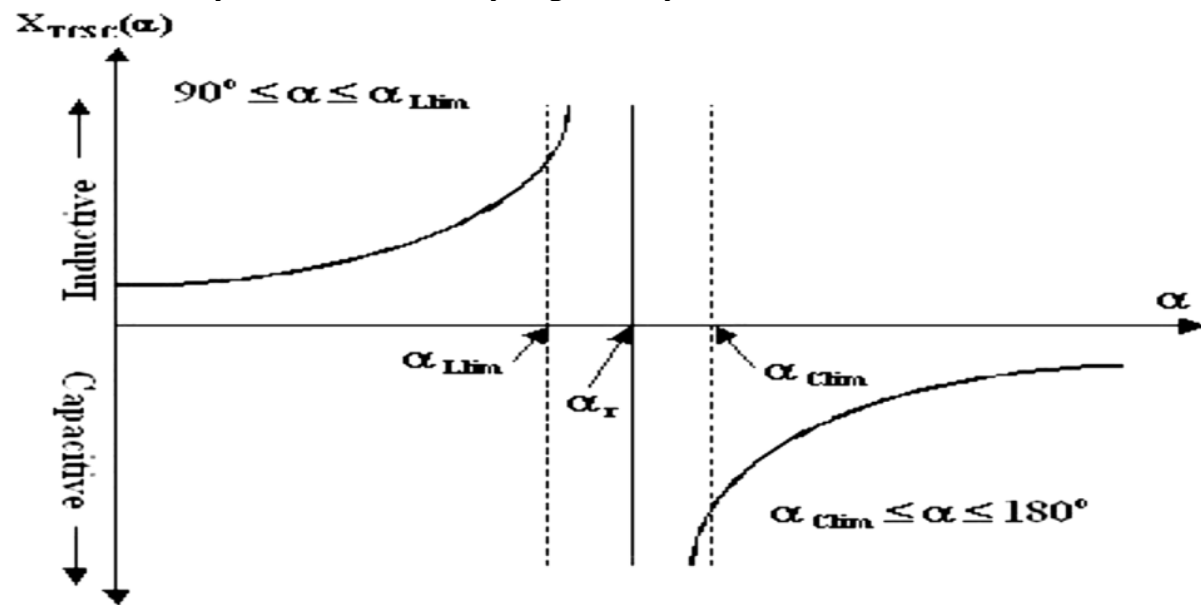

Fig. 2.4 XTCSC vs. $\alpha$ Characteristic of TCSCs

\section{PROBLEM FORMULATION}

The main object of the research is to improve the voltage at the buses of a power system. And for minimization of operating cost, the evolutionary algorithms are used. These algorithms will help to improve the voltage profile at buses using FACTS devices. The selection of the location is done according to flow of reactive power in the lines.

Mathematically, the problem may be given as maximizing the voltage at the buses,

DOI Number: https://doi.org/10.30780/specialissue-ICRDET-2019/008 


$$
f_{v}=\frac{1}{N \sqrt{\sum_{j=1}^{j=N}\left(V_{n}-V_{j}\right)^{2}}}
$$

In which $V n$ is voltage level, $V_{j}$ is voltage of the $j t h$ bus and $\mathrm{N}$ is the number of buses of the network.

And where constraints are

$P_{i}^{\min } \leq P_{i} \leq P_{i}^{\max }$; (Active power constraints)

$Q_{i}^{\min } \leq Q_{i} \leq Q_{i}^{\max } ;$ (Reactive power constraints)

$V_{i}^{\min } \leq V_{i} \leq V_{i}^{\max } ;$ (Voltage magnitude constraints)

$t_{t}^{\min } \leq t_{k} \leq t_{k i}^{\max }$

$Q g_{i}^{\min } \leq Q g_{i} \leq Q g_{i}^{\max } ;$ (Existing nodal reactive capacity constraints

\section{TEACHING-LEARNING-BASED OPTIMIZATION TECHNIQUE}

Teaching-learning is a very important method wherever each individual tries to find out one thing from different individuals to enhance themselves. Teaching-Learning-Based optimization (TLBO) integrates the standard development of teaching learning development of a schoolroom. The algorithmic rule imitates 2 elementary methods of teaching:

Through the teacher (known because the teacher phase)

$>$ Communication with alternative learners (known because the learner phase).

\subsection{Teaching phase}

Teaching phase of the algorithmic rule imitates the learning of the students (i.e. learners) by the teacher. Throughout this phase, a teacher conveys information among the students and makes an attempt to extend the mean results of the class. Consider, there are ' $m$ ' range of subjects (i.e. variables) offered to ' $n$ ' range of learners (i.e. population size, $\mathrm{k}=1,2 \ldots \mathrm{n}$ ). At any serial teaching-learning cycle, $\mathrm{i}, \mathrm{Mj}$, i is that the mean results of the learners during a specific subject ' $\mathrm{j}$ ' $(\mathrm{j}=$ one, $2 . \mathrm{m})$. Since a teacher is that the most intimate with and knowledgeable person on a subject matter, the most effective learner within the entire population is taken into account a teacher within the algorithmic rule. Let Xtotal-kbest,i be the results of the most effective learner considering all the topics who is known as a teacher for that cycle. The teacher can place most effort into increasing the information level of the full class; however learners can gain information in step with the standard of teaching delivered by a teacher and therefore the quality of learners present within the class. Considering this reality, the distinction between the results of the teacher and therefore the mean results of the learners in every subject is expressed as:

$$
\text { Difference_Mean }{ }_{j, i}=r_{i}\left(X_{j, k b e s t, i}-T F \times M_{j, i}\right)
$$

where $\mathrm{Xj}$,kbest, $\mathrm{i}$ is that the results of the teacher (i.e. best learner) in subject $\mathrm{j}$. TF is that the teaching factor, that decides the worth of mean to be modified, and ri is that the random number within the range[0, 1]. The worth of TF may be either one or two. the value of TF is determined arbitrarily with equal chance is:

$$
T F=\operatorname{round}[1+\operatorname{rand}(0,1)\{2-1\}]
$$

Where rand is that the random range within the vary $[0,1]$. TF isn't a parameter of the TLBO algorithmic program. Worth of TF isn't given as an input to the algorithmic program and its value is at random determined by the algorithmic program utilizing equation supported the Difference_Meanj, i, the present answer is updated within the teacher phase consistent with the subsequent expression:

$$
X_{j, k, i}^{\prime}=X_{j, k, i}+\text { Difference } \text { Mean }_{j, i}
$$

Where $X^{\prime} j, k, i$ is that the updated value of $X j, k, i$. Accept $X^{\prime} j, k, i$ if it provides a more robust function value. All the accepted operate values at the top of the teacher phase are maintained, and these values become the input to the learner phase. it should be noted that the values of ri and TF have an effect on the performance of the TLBO algorithmic rule. $r_{i}$ is the random range within the vary $[0,1]$ and TF is that the teaching factor. However, the values of $r_{i}$ and TF are generated arbitrarily within the algorithmic rule and these parameters don't seem to be provided as input to the algorithmic rule (unlike provision crossover and mutation possibilities in GA, inertia weight and psychological feature and social parameters in PSO, and colony size and limit in ABC, etc.).

Thus, calibration of $r_{i}$ and TF isn't needed within the TLBO algorithmic rule (unlike the calibration of crossover and mutation possibilities in GA, inertia weight and psychological feature as well different parameters in PSO, and colony size and limit in ABC, etc.). TLBO needs calibration of solely the common control parameters like population size and variety of generations, for its operating. The same management parameters are needed for the operating of all population primarily based optimization algorithms. Thus, TLBO may be referred to as an algorithmic which is more of rule dependent and less affected by the parameters.

\subsection{Learning phase}

This section of the algorithm imitates about the learning of the students among themselves through communication and interaction. The students will learn information by reviewing and collaborating with several other students. A student can learn new info if the opposite students have a lot of information than him or her. 
The learning development of this section is expressed below. at random choose 2 learners, $\mathrm{P}$ and $\mathrm{Q}$, specified $\mathrm{X}^{\prime}$ total-P,i $\neq \mathrm{X}^{\prime}$ total-Q,I, where, $\mathrm{X}^{\prime}$ total-P,i and $\mathrm{X}^{\prime}$ total-Q,i are the updated values of Xtotal-P,i and Xtotal-Q,i, severally, at the top of the teacher phase.

$$
\begin{aligned}
& X{ }_{j, P, i}=X{ }_{j, P, i}+r_{i}\left(X{ }_{j, P, i}-X{ }_{j, Q, i}\right) \text { If } X{ }_{\text {total }-P, i}<X_{\text {total }-Q, i} \\
& X{ }^{\prime}{ }_{j, P, i}=X{ }_{j, P, i}+r_{i}\left(X{ }_{j, Q, i}-X{ }_{j, P, i}\right) \text { If } X^{{ }_{\text {total }-Q, i}}<X^{\prime}{ }_{\text {total }-P, i},
\end{aligned}
$$

The above equations are for minimization problems, the below is true for maximization problems. Accept $\mathrm{X}, \mathrm{j}, \mathrm{P}, \mathrm{i}$ if it will give a better function value.

\section{RESULTS}

For IEEE 30 bus system, TLBO is applied for maximization of voltage. Table 1 shows the number of controlling variables. Table 2 shows the location of the SVCs and TCSCs. Similarly Table 3 shows the voltage of buses at different reactive loading with and without TLBO.

Table -5.1 Number of controlled variables

\begin{tabular}{|l|l|l|l|}
\hline SVC & TCSC & Transformer tap & Reactive generation of generator \\
\hline 4 & 4 & 4 & 5 \\
\hline
\end{tabular}

Table-5.2 Location of SVC and TCSC in the network

\begin{tabular}{|c|c|c|c|c|c|c|c|}
\hline \multicolumn{3}{|c|}{ Location of SVCs at the Buses } & \multicolumn{4}{c|}{ Location of TCSCs placed in lines } \\
\hline 21 & 7 & 10 & 15 & 25 & 41 & 28 & 26 \\
\hline
\end{tabular}

Table -5.3 Voltage Profile at SVC Bus with TLBO

\begin{tabular}{|c|c|c|c|c|}
\hline \multirow{2}{*}{ SVC BUS } & \multicolumn{4}{|c|}{ VOLTAGE } \\
\cline { 2 - 5 } & Without TLBO & \multicolumn{3}{|c|}{ With TLBO } \\
\cline { 2 - 5 } & & $100 \%$ & $110 \%$ & $120 \%$ \\
\hline 21 & 1.0311 & 1.0786 & 1.0641 & 1.1089 \\
\hline 7 & 1.0085 & 1.0059 & 1.0139 & 1.1147 \\
\hline 10 & 1.0364 & 1.0867 & 1.0724 & 1.1006 \\
\hline
\end{tabular}

\section{CONCLUSION}

A novel optimization methodology, TLBO, is conferred supported the philosophy of the teaching-learning method and its performance is checked by experimenting with totally different benchmark issues with different characteristics. The effectiveness of TLBO is additionally checked for various performance criteria, like active power loss, reactive power flow, average range of perform evaluations needed, convergence rate, etc. The results show the higher performance of TLBO applied for voltage improvement. Also, TLBO shows a far better performance with less process effort for giant scale issues.

\section{REFERENCES}

[1] Biplab Bhattacharyya and Rohit Babu,"Teaching Learning Based Optimization algorithm for reactive power planning”, International Journal of Electrical Power \& Energy Systems, Vol.81, pp. 248-253, 2016

[2] E. Ghahremani and I. Kamwa, "Optimal placement of multiple-type FACTS devices to maximize power system loadability using a generic graphical user interface”, IEEE Transactions on Power Systems, Vol. 28, No. 2, pp. 764 - 778, Aug. 2012

[3] P. Savsani, R. L. Jhala and V. J. Savsani, "Optimized trajectory planning of a robotic arm using teaching learning based optimization (TLBO) and artificial bee colony (ABC) optimization techniques", IEEE International Systems Conference (SysCon), 15-18 April, Orlando, 2013

[4] R. V. Rao, V. J. Savsani and J. Balic, "Teaching Learning Based Optimization Algorithm for Constrained and Unconstrained Real Parameter Optimization Problems”, Engineering Optimization, Vol. 44, No. 12, pp. $1447-1462,2012$

[5] R. V. Rao, V. J. Savsani and D. P. Vakharia, "Teaching- Learning-Based Optimization: A Novel Method for Constrained Mechanical Design Optimization Problems", Computer-Aided Design, Vol. 43, No. 1, pp. 303-315, 2011.

DOI Number: https://doi.org/10.30780/specialissue-ICRDET-2019/008 
[6] Jaianand Jayaraman and Arun Sekar, "Study of Reactive Power/Voltage Sensitivities in Interconnected Power System Networks", IEEE 42nd South Eastern Symposium on System Theory University of Texas at Tyler TX, March 7-9, USA, 2010

[7] F.A. Althowibi and M.W. Mustafa, "Voltage Stability Calculations in Power Transmission Lines: Indications and Allocations", IEEE International Conference on Power and Energy (PECon2010), Nov 29 - Dec 1, Kuala Lumpur, Malaysia, 2010

[8] B. Bhattacharyya, S.K. Goswami, R.C. Bansal, "Loss sensitivity approach in evolutionary algorithms for reactive power planning", Electrical Power Component System, 2009.

[9] Chandrabhan Sharma and Marcus G. Ganness, "Determination of Power System Voltage Stability Using Modal Analysis", IEEE at POWERENG 2007, April 12, Setubal, Portugal, 2007

[10] B. Mahdad, T. Bouktir, and K. Srairi, "Strategy of location and control of FACTS devices for enhancing power quality", IEEE Mediterranean Electrotechnical Conference, MELECON, Malaga, 16-19 May, 2006.

[11] Musirin and T. K. Abdul Rahman, "Estimating Maximum Loadability for Weak Bus Identification Using Fast Voltage Stability Index”, IEEE Power Engineering Review, pp. 50-52, November 2002

[12] Hadi Saadat, "Power System Analysis", Tata McGraw-Hill Edition,2002

[13] C.A. Cañizares and Z.T. Faur, "Analysis of SVC and TCSC Controllers in Voltage Collapse", IEEE Trans. Power Syst., Vol. 14, No. 1, pp. 158-165, February, 1999 